\title{
ARTÍCULO 18: EL DERECHO A LA LIBERTAD RELIGIOSA ${ }^{1}$
}

\author{
Rosa Mentxaka
}

Professora catedrática de Direito Romano no Departamento de Direito Romano e Eclesiástico (Universidad del País Vasco/Euskal Herriko Unibertsitatea - Espanha) rosa.mentxaka@ehu.es

Sumário: Introdução. 1. El ayer. 2. El hoy. 3. El mañana.

Resumen: El texto, partiendo del artículo 18 de la Declaración Universal de los Derechos Humanos, exponer los principales textos jurídicos que a nivel internacional, europeo y estatal han desarrollado este artículo. Tras una breve exposición histórica referida sólo a algunos de los antecedentes existentes en la cultura jurídica europea, el artículo se centra en la exposición cronológica del contenido del derecho a la libertad religiosa en documentos internacionales de distinta naturaleza jurídica (desde declaraciones adoptadas por la Asamblea General de las Naciones Unidas hasta Pactos o Convenios Internacionales). Tras comenzar por la Declaración Universal (1948), se sigue con el Convenio para la protección de los Derechos y las Libertades Fundamentales (1950), el Pacto internacional de los Derechos Civiles y Políticos (1966), la Declaración sobre la eliminación de todas las formas de intolerancia y discriminación fundadas en la religión o las convicciones (1981), para concluir el apartado dedicado a la Regulación Internacional con la referencia existen a la libertad religiosa en la Carta de los Derechos Fundamentales de la Unión Europea (2000). Otro apartado importante se dedica al tratamiento del tema en la Constitución española, que recogió dicho derecho fundamental así como a su desarrollo posterior en la ley Orgánica de Libertad religiosa (1980). De este conjunto de disposiciones puede deducirse que en el Estado español los textos normativos proclaman sin ningún género de dudas la libertad religiosa garantizándola tanto a las personas individuales como a las Confesiones sin más limitaciones que las necesidades del orden público establezcan. Ello se concreta en el máximo respeto tanto a la creencia interna (reconocimiento de un ámbito íntimo de creencias) como a la manifestación externa (que permite a los ciudadanos actuar con arreglo a sus propias convicciones y mantenerlas frente a terceros) así como a la no creencia y su expresión. Además, la relación entre el Estado y las Confesiones religiosas está basada en dos elementos: la separación del Estado de las Confesiones y la neutralidad positiva que implica la intervención de los poderes públicos mediante actividades encaminadas a hacer efectivo ejercicio de la libertad a todos por igual ${ }^{2}$. Ahora bien, la aplicación práctica de esta legislación ha dado lugar en algunas ocasiones a un régimen dispar por lo que se ha reivindicado por parte de la doctrina la necesidad de una nueva regulación que no produzca trato discriminatorio ni entre las personas ni entre las Confesiones religiosas como tal.

Palabras-clave: Religión. Libertad religiosa. Derechos Humanos.

\footnotetext{
${ }^{1}$ Las presentes páginas deben insertarse en el Proyecto de Investigación EHU13/06: Cristianismo y Derecho Romano.

${ }^{2} \mathrm{Al}$ respecto desarrollando el tema con profundidad: CASTRO JOVER, Laicidad cit.
} 


\section{El Ayer}

\subsection{Consideraciones previas}

Se da la paradoja que siendo mi especialidad el Derecho Romano haya aceptado el compromiso de sintetizar en unas breves páginas la problemática que encierra un tema tan universal $^{3}$, actual ${ }^{4}$, importante ${ }^{5}$ y difícil por su interdisciplinariedad ${ }^{6}$ como el que me ocupa, que, en alguna medida, también se vivió en una sociedad plural y compleja como lo fue la romana de la época imperial.

\subsection{Mínimas referencias de carácter histórico}

Es mi intención mencionar aquí sólo algunos de los antecedentes europeos a la libertad religiosa que, así formulada, aparece en la Declaración de los Derechos del hombre y del ciudadano de $1789^{7}$, dejando de lado los precedentes que, en otras sociedades y culturas, hayan podido existir sobre la cuestión ${ }^{8}$. Como sabemos, el mundo greco-romano era politeísta, lo que presuponía la existencia de una pluralidad de cultos. En ese contexto tolerante se permitió la práctica del Judaísmo y también surgió el Cristianismo, religión que se difundió con éxito por todo el Imperio hasta principios del siglo III y se erigió en importante minoría religiosa. Desde mediados

\footnotetext{
${ }^{3}$ Sirva como dato el hecho conocido de que el derecho a la libertad religiosa ha quedado recogido, como se expondrá en este mismo texto, en la Declaración Universal de Derechos del Hombre. Además, en su $42^{\circ}$ período de sesiones, la Comisión de Derechos Humanos de Naciones Unidas decidió, mediante su resolución 1986/20 de 10 de marzo de 1986, designar un relator especial para que examinara los incidentes y las actividades de los gobiernos que tuvieran lugar en todas partes del mundo y que no se ajustaran a las disposiciones de la Declaración. A partir del año 1988 los distintos relatores sucesivamente nombrados han venido presentando informes a la Comisión de Derechos Humanos así como a la Asamblea General, informes que se pueden consultar en: http://documents.un.org/simple.asp.

${ }^{4}$ Basta citar a título de ejemplo el problema suscitado por la retirada de los crucifijos de las aulas de los colegios públicos que ha dado lugar a una sentencia del tribunal de Estrasburgo de 3 de noviembre de 2009. Affaire Lautsi c. Italie (Requête 30814-06). De la cuantiosa literatura en múltiples idiomas que ha generado este caso voy a citar sólo algunos artículos: PAREJO GUZMÁN, M. J., "Reflexiones sobre el asunto Lautsi y la jurisprudencia del TEDH sobre símbolos religiosos: hacia soluciones de carácter inclusivo en el orden público europeo”, en Revista de Derecho Comunitario Europeo, 37 (2010) 865-895; TOSCANO, M. , "La lezione di Strasburgo: i casi Lombardi Vallauri e Lautsi", Il Diritto ecclesiastico, 120/3-4 (2009) 505-540 y PANARA, C., "Lautsi v. Italy": The Display of Religious Symbols by the State", European public law, 17/1 (2011) 139-168.
}

${ }^{5}$ A nivel individual la religión, o su ausencia, constituye uno de los elementos fundamentales de la identidad, la concepción vital, y las creencias de los seres humanos; a nivel académico, la libertad religiosa, ideológica y de conciencia se presenta como el objeto de la disciplina Derecho Eclesiástico del Estado. Al respecto: LLAMAZARES FERNÁNDEZ, D., Derecho de la libertad de conciencia. Vol. I. Conciencia, tolerancia y laicidad, 4. ed., Thomson Civitas, Cizur Menor 2011, 34 ss.

${ }^{6}$ Basta citar a título de ejemplo el problema suscitado por la retirada de los crucifijos de las aulas de los colegios públicos que ha dado lugar a una sentencia del tribunal de Estrasburgo de 3 de noviembre de 2009. Affaire Lautsi c. Italie (Requête 30814-06). De la cuantiosa literatura en múltiples idiomas que ha generado este caso voy a citar sólo algunos artículos: PAREJO GUZMÁN, M. J., "Reflexiones sobre el asunto Lautsi y la jurisprudencia del TEDH sobre símbolos religiosos: hacia soluciones de carácter inclusivo en el orden público europeo”, en Revista de Derecho Comunitario Europeo, 37 (2010) 865-895; TOSCANO, M. , "La lezione di Strasburgo: i casi Lombardi Vallauri e Lautsi", Il Diritto ecclesiastico, 120/3-4 (2009) 505-540 y PANARA, C., "Lautsi v. Italy": The Display of Religious Symbols by the State", European public law, 17/1 (2011) 139-168.

${ }^{7}$ Concretamente en su artículo 10 recoge tal derecho al afirmar que: "Ningún hombre debe ser molestado por razón de sus opiniones, ni aún por sus ideas religiosas, siempre que al manifestarlas no se causen trastornos del orden público establecido por la ley".

${ }^{8}$ Por ejemplo, la Declaración de Derechos de Virginia de 1776 que en su artículo 16 recogía el derecho al libre ejercicio de la religión. Reproduce este documento así como otros de la Edad Moderna y Contemporánea referidos a derechos fundamentales en el mundo occidental: AAVV, (Eds. PECES-BARBA, G.- LLAMAS GASCÓN, A.-FERNÁNDEZ LIESA, C.), Textos básicos de Derechos humanos. Con estudios generales y especiales y comentarios a cada texto nacional e internacional, Aranzadi, Elcano Navarra 2001, 43 ss. 
del citado siglo, al considerarse que su práctica atentaba a los principios básicos de lealtad política a Roma, fue objeto de persecución sistemática hasta que Constantino, haciéndose eco de las medidas adoptadas por Galerio en el 311, promulgó el llamado Edicto de Milán del 313i? que reconoció la libertad de culto también para los cristianos ${ }^{9}$, religión que se convirtió con Teodosio I en el 380 en la oficial del Imperio ${ }^{10}$. A la caída del Imperio Romano, el carácter universal del Cristianismo le produjo fuertes tensiones y enfrentamientos con otras religiones con las que compartía ámbito geográfico y monoteísmo (por ejemplo con el Judaísmo al producirse la expulsión de los judíos en España, o con el mundo islámico en las cruzadas). Pero también en su propio seno se dieron discrepancias y la Inquisición ${ }^{11}$ o las Guerras de Religión ${ }^{12}$ son un buen ejemplo de ello. En Francia, con el fin de resolver las luchas entre católicos y calvinistas, se promulgó el Edicto de Nantes ${ }^{13}$ y los enfrentamientos iniciales entre partidarios de la Reforma Protestante y la Contra-Reforma (1500-1650) acabaron en convivencia, gracias a la Paz de Augsburgo de $1555^{14}$ inicialmente y al Tratado de Westfalia de $1648^{15}$ con posterioridad. Pero las primeras conquistas religiosas en la Europa feudal occidental se habían producido con antelación, cuando las confrontaciones entre la nobleza, la iglesia y la monarquía hicieron posible la aparición de lo que se conoce como $L a$ Magna Carta Libertatum, promulgada en 1215 por Juan I de Inglaterra y que iniciaba reconociendo la libertad de la Iglesia frente al monarca ${ }^{16}$. Entre otros, estos precedentes explican que, tras el fracaso colectivo que supuso la segunda Guerra Mundial, unas Naciones Unidas incipientes se plantearan la elaboración de un texto universal.

9 Nos informa de ello tanto Lactancio, Mort., 48,2 como Eusebio de Cesarea, HE, X,5,4 texto que aquí se reproduce en castellano: “...Cuando yo, Constantino Augusto, y yo, Licinio Augusto, nos reunimos felizmente en Milán..... decidimos sobre todo distribuir unas primeras disposiciones en que se aseguraba el respeto y el culto a la divinidad, esto es, para dar, tanto a los cristianos como a todos en general, libre elección en seguir la religión que quisieran.....". Al respecto por ejemplo: FERNÁNDEZ UBIÑA, J., "Constantino y el triunfo del Cristianismo en el Imperio Romano", AAVV., (Coords. STOMOMAYOR, M. - FÉRNANDEZ UBIÑA, J.), Historia del Cristianismo. 1. El mundo Antiguo. Editorial Trotta, Madrid 2003, 329ss.

${ }^{10}$ CTh. 16,1,2. Desarrolla el tema por ejemplo: ENSSLIN, W. Die Religionspolitik des Kaisers Th. des Grossen, (SBAW 1953,2) München 1953 y BLÁZQUEZ, J. M., "El cristianismo religión oficial del Imperio", Historia 16, XXI (1997) 56-65.

${ }^{11}$ Entre la múltiple bibliografía: KAMEN, H., La inquisición española. Una revisión histórica. 2. Ed., Crítica, Barcelona 2004..

${ }^{12}$ Ver: DUNN, R. S., The Age of Religious Wars 1559-1715, 2. Ed., W.W. Norton \& C., New York 1979.

${ }^{13}$ El texto viene precedido de otros que habían ido surgiendo durante los cuatro decenios previos que ya habían aceptado en algunos lugares la libertad de culto para los protestantes. En 1598 mediante este texto Enrique IV de Francia sienta las bases de la coexistencia entre protestantes y católicos al reconocer plena libertad de conciencia a los protestantes franceses garantizándoles incluso la protección contra la Inquisición cuando viajaran al extranjero. El texto es accesible en francés en: http://huguenotsweb.free.fr/histoire/edit_nantes.htm y en castellano: PECES-BARBA, Textos cit., 51 ss.; LLAMAZARES, Derecho, Vol. I, cit., 96 ss. atribuye a este Edicto la separación entre unidad política y unidad de fe religiosa y en consecuencia, la desconfesionalización del Estado.

${ }^{14}$ Legalizó el Luteranismo al permitir a los príncipes alemanes elegir la confesión a practicar. Vid. texto en:http:// www.lwl.org/westfaelischegeschichte/portal/Internet/finde/langDatensatz.php?urlID=739\&url_tabelle=tab_quelle. Así como PARKER, G., La guerra de los Treinta Años, Crítica, Barcelona 1988.

${ }^{15}$ Compuesto en realidad por los acuerdos de Münster y Osnabrück se ha considerado el primer Tratado Internacional multilateral. Por lo que se refiere a la libertad religiosa, reconoce, confirma y ratifica el primero en los parágrafos 28 y 49 el libre ejercicio de la religión. El acuerdo de Osnabrück trata en su capítulo V de las relaciones entre las confesiones en el Imperio. Ambos textos disponibles en alemán en: http://www.lwl.org/westfaelischegeschichte/ portal/Internet/finde/langDatensatz.php?urlID=741\&url_tabelle=tab_quelle. LLAMAZARES, Derecho, Vol. I, cit., 91 subraya que entre las partes que llegan a un acuerdo no está nunca la Iglesia ni católica ni protestante sino que estamos ante acuerdos secularizados.

${ }^{16}$ Versión en inglés en la British Library://www.bl.uk/treasures/magnacarta/translation/mc_trans.html y en castellano: PECES-BARBA, Textos cit., 34 ss.. 


\section{EL HoY}

También en este punto me limitaré a mencionar únicamente algunos de los documentos más relevantes que en diferentes niveles (normas internacionales, Derecho de la Unión Europea y legislación estatal ${ }^{17}$ ) se han dado sobre el tema, tomando como punto de partida el artículo correspondiente de la Declaración Universal ${ }^{18}$.

\subsection{Algunas normas internacionales que se refieren a la libertad religiosa}

Recojo aquí sólo ${ }^{19}$ algunos instrumentos ${ }^{20}$ cuya interrelación ha sido subrayada por la doctrina ${ }^{21}$, de naturaleza jurídica muy diversa y, por consiguiente, con distinto carácter vinculante ${ }^{22}$. Su reproducción permitirá apreciar en algunas ocasiones el calco casi mimético entre unos artículos y otros, pese a proceder de distintos cuerpos jurídicos ${ }^{23}$.

\footnotetext{
${ }^{17}$ No se va a hacer referencia a la legislación autonómica que pueda existir y trate de la cuestión religiosa. Al respecto por ejemplo: LLAMAZARES, Derecho, Vol. I cit., 379 ss.; BRIONES MARTÍNEZ, I. M., Análisis general de la normativa estatal y autonómica sobre inmigración en España. Inmigración, cultura y factor religioso. Difusión jurídica, Madrid, 2007 y AAVV, (Dir. GARCÍA GARCİA, R.), La libertad religiosa en las Comunidades Autónomas. 25 años de su regulación. Institut d'Estudis Autonòmics, Barcelona 2008.

${ }^{18}$ Sobre la totalidad de textos existentes al respecto puede consultarse por ejemplo el compendio de Legislación Eclesiástica, AAVV, (Eds. FORNÉS, J.- BLANCO, M.- CASTILLO, B. y PÉREZ-MADRID, F.), Thomson-Aranzadi, 11. Ed., Cizur Menor 2011.
}

${ }^{19}$ No se van a traer a este enunciado por razones varias (espacio, tratar indirectamente nuestro tema y no ser mi objetivo la exposición exhaustiva de la regulación internacional existente sobre la libertad religiosa): a.- Los convenios de Ginebra, en particular el de 1949 y los protocolos posteriores (en: http://www.icrc.org/spa/war-and-law/ treaties-customary-law/geneva-conventions/index.jsp) que, con el propósito de minimizar los efectos de la guerra, establecen la no discriminación por razones de religión a heridos, enfermos de las fuerzas armadas así como a los prisioneros de guerra; b.- la Declaración sobre los derechos de las personas pertenecientes a minorías nacionales, religiosas y lingüisticas (accesible en: http://www2.ohchr.org/spanish/law/minorias.htm) que, en su artículo primero, reconoce a las minorías religiosas el derecho a practicar su propia religión en público o en privado así como a formar y mantener sus propias asociaciones); c.- El pacto internacional de Derechos Económicos sociales y culturales (disponible en: http://www2.ohchr.org/spanish/law/cescr.htm) donde, en relación con el derecho a la educación, se establece en el artículo 13 que éste debe favorecer la comprensión, tolerancia y la amistad entre todas las naciones y entre todos los grupos raciales, étnicos o religiosos; d.- La Convención sobre los Derechos del Niño (accesible en: http://www2.ohchr.org/spanish/law/crc.htm) que, en diversos artículos --2,1; 5; 14, etc.--, menciona el derecho del niño a que el Estado respete su libertad de religión.

${ }^{20} \mathrm{Si}$ bien los voy a mencionar siguiendo un orden cronológico es necesario precisar que los cuatro primeros son los que ciertamente tienen cabida bajo el epígrafe de normas internacionales que encabeza este apartado, mientras que la Carta de los Derechos fundamentales de la Unión pertenece propiamente al Derecho de la Unión Europea. Esta estructura se sigue en LLAMAZARES, D., Derecho eclesiástico del Estado, 9.ed., Ariel, Barcelona 2008, 5.

${ }^{21}$ LLAMAZARES, Derecho, Vol. I, cit., 192 ss; CASTRO JOVER, A., "La tutela de la libertad religiosa en la Unión Europea y su incidencia en el Ordenamiento interno español”, AAVV, (Coords. BARRANCO AVILES, M. C., - CELADOR ANGÓN, O. y VACAS FERNÁNDEZ, F.), Perspectivas actuales en las fuentes del Derecho, Dykinson 2011, Madrid 2011, 98ss. y TAYLOR, P. M., Freedom of Religion: UN and European Human Rihgts Law and Practice, Cambridge University Press, Cambridge 2005, 7ss.

${ }^{22}$ Sobre el valor vinculante o no de las declaraciones por ejemplo: LLAMAZARES, Derecho, Vol. I, cit., 187 y CARRILLO SALCEDO, A., "Algunas reflexiones sobre el valor jurídico de la Declaración Universal de Derechos Humanos”, AAVV., (Coord. PÉREZ GONZÁLEZ, M.), Hacia un Nuevo Orden Internacional y Europeo. Homenaje al Profesor Manuel Diez de Velasco, Tecnos, Madrid 1993, 167-178.

${ }^{23}$ Por ejemplo, el artículo 10 de la Carta de Derechos Fundamentales de la Unión Europea recoge de manera casi idéntica el artículo 9 del Convenio Europeo de Derechos Humanos. Breve comentario a la variación: LLAMAZARES, Derecho, Vol. I, cit., 191. 


\subsubsection{La Declaración Universal (1948) ${ }^{24}$}

El punto de partida del reconocimiento a la libertad religiosa en un texto internacional de carácter universal lo constituye la Declaración Universal de 1948, que en su artículo 18 establece el derecho de toda persona a la libertad de pensamiento, conciencia y religión ${ }^{25}$; ello se concreta en que, todo ser humano o comunidad pueda elegir libremente su religión o creencia, practicarla o propagarla, tanto en el ámbito público como privado, así como abstenerse de cualquier práctica religiosa o cambiar de una religión a otra ${ }^{26}$. En nuestro caso concreto, el artículo $10.2^{27}$ de la Constitución fija la necesidad de interpretar las normas referidas a derechos fundamentales de acuerdo con la Declaración Universal.

\subsubsection{Convenio Europeo para la protección de los Derechos Humanos y de las Libertades Fundamentales (1950) ${ }^{28}$}

Adoptado en Roma el cuatro de noviembre de 1950, no se limita a proclamar los derechos sino que incorpora un sistema de control jurisdiccional de las violaciones ${ }^{29}$; en su

24 El 10 de diciembre de 1948, la Asamblea General de las Naciones Unidas reunida en Nueva York aprobó y proclamó la Declaración Universal de Derechos Humanos (Resolución 217, A, III) cuyo texto completo es accesible en: www.un.org/es/documents/udhr/. Sobre ella por ejemplo las obras de: ORAÁ, J. - GÓMEZ ISA, F., La Declaración Universal de Derechos Humanos. Un Breve Comentario en su Cincuenta Aniversario, Universidad de Deusto, Bilbao 1998; MORSINK, J., The Universal Declaration of Human Rights. Origins, drafting, and intent, University of Pennsylvania Press, Philadelphia 1999; PONS RAFOLS, X. (Cord.), La Declaración Universal de los Derechos Humanos. Comentario artículo por artículo. Icaria. Barcelona 1998, así como la abundante bibliografía recogida en: http: //www2.ohchr.org/english/issues/education/training/docs/UDHR_Bibliography.pdf.

25 Artículo 18: Toda persona tiene derecho a la libertad de pensamiento, de conciencia y de religión; este derecho incluye la libertad de cambiar de religión o de creencia, así como la libertad de manifestar su religión o su creencia, individual y colectivamente, tanto en público como en privado, por la enseñanza, la práctica, el culto y la observancia. Véase sobre el tema por ejemplo: JONG, C. D. de, The freedom of thought, conscience and religion or belief in the United Nations (1946-1992), Intersentia-Hart, Oxford 2000; SOUTO GALVÁN, E., El reconocimiento de la libertad religiosa en Naciones Unidas, Marcial Pons, Madrid y otras, 2000 y, sobre todo: AAVV, (Ed. GHANEA N.), Religion and human rights. Critical concepts in religious studies, 4 vols. Routledge Major Works, London 2009.

${ }^{26}$ En estrecha relación con este artículo, encontramos en la Declaración otros como el 20 que consagra la libertad de reunión y asociación (1.Toda persona tiene derecho a la libertad de reunión y de asociación pacíficas. 2. Nadie podrá ser obligado a pertenecer a una asociación ) y el 26 que contempla el derecho a la educación, que debe favorecer, entre otras cosas, la tolerancia entre todas las naciones y todos los grupos étnicos o religiosos y que también reconoce el derecho de los padres a elegir la educación que deseen para sus hijos (1.Toda persona tiene derecho a la educación. La educación debe ser gratuita, al menos en lo concerniente a la instrucción elemental y fundamental. La instrucción elemental será obligatoria. La instrucción técnica y profesional habrá de ser generalizada; el acceso a los estudios superiores será igual para todos, en función de los méritos respectivos. 2. La educación tendrá por objeto el pleno desarrollo de la personalidad humana y el fortalecimiento del respeto a los derechos humanos y a las libertades fundamentales; favorecerá la comprensión, la tolerancia y la amistad entre todas las naciones y todos los grupos étnicos o religiosos, y promoverá el desarrollo de las actividades de las Naciones Unidas para el mantenimiento de la paz. 3. Los padres tendrán derecho preferente a escoger el tipo de educación que habrá de darse a sus hijos).

27 Artículo 10.2. Las normas relativas a los derechos fundamentales y a las libertades que la Constitución reconoce se interpretarán de conformidad con la Declaración Universal de Derechos Humanos y los tratados y acuerdos internacionales sobre las mismas materias ratificados por España. Sobre ello: LLAMAZARES, Derecho, Vol. I, cit., 375 ss., así como APARICIO PÉREZ, M. A., "La cláusula interpretativa del artículo 10.2 de la Constitución Española, como cláusula de integración y apertura constitucional a los derechos fundamentales", Jueces para la democracia, 6 (1989) 9-18.

28 Disponible en la dirección electrónica: http://www.echr.coe.int/NR/rdonlyres/1101E77A-C8E1-493F-809D 800CBD20E595/0/ESP_CONV.pdf. También en el BOE núm. 108 de 6 de mayo; rect. BOE núm. 140 de 12 de junio. Véase al respecto por ejemplo: STOFFEL VALLOTTON, N., "La adhesión de la Unión Europea al Convenio Europeo para la Protección de los Derechos Humanos y de las Libertades Fundamentales: evolución de la cuestión, previsiones y posibles consecuencias", AAVV., (Coord. MARTÍN y PÉREZ DE NANCLARES, J.), El Tratado de Lisboa: la salida de la crisis constitucional: Jornadas de la Asociación Española de Profesores de Derecho Internacional-AEPDIRI-celebradas en Madrid el 17 y 18 de diciembre de 2007, Portal Derecho S. A., Madrid 2008, 179-198.

29 Vid.: LLAMAZARES, Derecho, Vol. I, cit., 187 ss. 
artículo 9 recoge la libertad de pensamiento, conciencia y religión, conteniendo una referencia expresa a la libertad de manifestar la religión de manera individual o colectiva, en público o en privado, mediante culto, enseñanza u observación de ritos y sometiéndola a los límites previstos en la ley ${ }^{30}$. Su interpretación y aplicación ha correspondido al Tribunal Europeo de Derechos Humanos de Estrasburgo que tiene jurisdicción sobre los Estados firmantes del Convenio ${ }^{31}$. Según MARTÍNEZ-TORRÓN ${ }^{32}$ y TAYLOR ${ }^{33}$ la jurisprudencia del Tribunal ha establecido la distinción entre, el forum internum y el externum de la libertad religiosa. El primero consiste en la libertad de creer (que comprende la libertad para elegir las propias creencias - religiosas o no -) y la libertad para cambiar de religión. El segundo se refiere a la libertad de actuar de acuerdo con la propia religión o creencia.

\subsubsection{Pacto internacional de Derechos Civiles y políticos (1966) $)^{34}$}

Este texto, aprobado por la Asamblea General de Naciones Unidas ${ }^{35}$, estableció un mecanismo de control, no jurisdiccional, pero vinculante para los Estados firmantes ${ }^{36}$, al crear un sistema de conciliación amistosa con intervención del Comité de Derechos Humanos - como principal órgano internacional encargado de vigilar la vigencia de los derechos enunciados en el Pacto - y en el supuesto de no conseguirse un arreglo, la Comisión de conciliación. En nuestro caso, entró en vigor el 27 de julio de $1977^{37}$ tras la oportuna ratificación; en su artículo 18 consagra la libertad religiosa al especificar que toda persona tiene derecho a la libertad de religión, derecho que incluye la libertad de tener o adoptar la religión o creencias que se deseen

${ }^{30}$ Libertad de pensamiento, de conciencia y de religión 1 . Toda persona tiene derecho a la libertad de pensamiento, de conciencia y de religión; este derecho implica la libertad de cambiar de religión o de convicciones, así como la libertad de manifestar su religión o sus convicciones individual o colectivamente, en público o en privado, por medio del culto, la enseñanza, las prácticas y la observancia de los ritos. 2. La libertad de manifestar su religión o sus convicciones no puede ser objeto de más restricciones que las que, previstas por la ley, constituyan medidas necesarias, en una sociedad democrática, para la seguridad pública, la protección del orden, de la salud o de la moral públicas, o la protección de los derechos o las libertades de los demás.

${ }^{31}$ Sobre el contenido del derecho de libertad religiosa en el Convenio Europeo de Derechos Humanos, vid. por ejemplo: MARTÍNEZ-TORRÓN, J., "Los límites a la libertad de religión y de creencia en el Convenio Europeo de Derechos Humanos", Revista General de Derecho Canónico y Derecho Eclesiástico del Estado, 2 (2003) edición electrónica en http: //wwww.iustel.com.

${ }^{32}$ Los límites cit., 4, artículo en el que se detiene en particular en el estudio jurisprudencial de las principales cuestiones suscitadas ante el tribunal europeo en materia de límites a la libertad religiosa, que son: 1. Proselitismo. 2. Lugares de culto. 3. Personalidad jurídica. 4. La autonomía de los grupos religiosos. 5. La libertad religiosa de los individuos dentro de una confesión religiosa. 6. La manifestación pública de ideas religiosas en el ámbito educativo. 7. El control gubernamental de las 'sectas'. 8. Las restricciones impuestas a la libertad de expresión a causa de la religión.

33 TAYLOR, Freedom cit., 115 ss.

${ }^{34}$ Disponible en: http://www2.ohchr.org/spanish/law/ccpr.htm. asi como en el BOE núm. 103, de 30 de abril de 1977. Sobre ello: TOMUSCHAT, C., "Pacto Internacional de Derechos civiles y políticos", en http://untreaty.un.org/cod/ avl/pdf/ha/iccpr/iccpr_s.pdf; NOWAK, M., UN Covenant on Civil and Political Rights, 2. Ed., N.P. Engel Publishers, Kehl, 2005; JOSEPH, S.- SCHULZ, J. - CASTÁN, M., International covenant on civil and political rights: Cases, commentary and materials, 2. Ed., Oxford U. Press, Oxford 2005.

${ }^{35}$ Consciente de la necesidad de un tratado internacional que completase y diera un valor jurídico plenamente vinculante a los derechos contenidos en la Declaración Universal por resolución núm. 2200 adoptada en su vigésimo primer periodo de sesiones con fecha de 16 de diciembre de 1966.

${ }^{36}$ En este sentido: LLAMAZARES, Derecho, Vol. I, cit., 188.

${ }^{37}$ Fue ratificado el 13 de abril de 1977 y publicado en el BOE núm. 193, de 30 de abril de 1977. 
así como la libertad de manifestar las creencias individual o colectivamente, en público y en privado mediante la celebración de ritos, prácticas y enseñanza ${ }^{38}$.

\subsubsection{Declaración sobre eliminación de todas las formas de intolerancia y discriminación en la religión o las convicciones $(1981)^{39}$}

Este texto fue aprobado por la Asamblea General de Naciones Unidas el 25.11.1981 mediante la resolución 36/55; la institución estaba preocupada por las manifestaciones de intolerancia y discriminación en el ámbito religioso que se advertían en algunos lugares del mundo; por ello, decidió adoptar las medidas necesarias para la rápida eliminación de dicha intolerancia en todas sus formas y manifestaciones y a prevenir y combatir la discriminación por motivos de religión o convicciones. En consecuencia, se planteó el reto de precisar su contenido haciendo una enumeración de las facultades que contiene el derecho a la libertad de religión ${ }^{40}$, al mismo tiempo que establece qué debe entenderse por intolerancia y discriminación basada en la religión o en las convicciones ${ }^{41}$, considerando que, cuando se produce da lugar a una violación de los derechos humanos ${ }^{42}$.

\footnotetext{
${ }^{38}$ Artículo 18. 1. Toda persona tiene derecho a la libertad de pensamiento, de conciencia y de religión; este derecho incluye la libertad de tener o de adoptar la religión o las creencias de su elección, así como la libertad de manifestar su religión o sus creencias, individual o colectivamente, tanto en público como en privado, mediante el culto, la celebración de los ritos, las prácticas y la enseñanza. 2. Nadie será objeto de medidas coercitivas que puedan menoscabar su libertad de tener o de adoptar la religión o las creencias de su elección. 3. La libertad de manifestar la propia religión o las propias creencias estará sujeta únicamente a las limitaciones prescritas por la ley que sean necesarias para proteger la seguridad, el orden, la salud o la moral públicos, o los derechos y libertades fundamentales de los demás. 4. Los Estados Partes en el presente Pacto se comprometen a respetar la libertad de los padres y, en su caso, de los tutores legales, para garantizar que los hijos reciban la educación religiosa y moral que esté de acuerdo con sus propias convicciones. Sobre si recoge tres derechos distintos o formas de un mismo derecho, así como su contenido: LLAMAZARES, Derecho, Vol. I, cit., 196ss.
}

39 Accesible en: http://www2.ohchr.org/spanish/law/intolerancia.htm. Al respecto: SULLIVAN, D. J., "Advancing the freedom of religion or belief through the UN declaration on the elimination of religious intolerance and discrimination", American Journal of International Law, 82, 3 (1988) 487-520.

40 Artículo 1: 1. Toda persona tiene derecho a la libertad de pensamiento, de conciencia y de religión. Este derecho incluye la libertad de tener una religión o cualesquiera convicciones de su elección, así como la libertad de manifestar su religión o sus convicciones individual o colectivamente, tanto en público como en privado, mediante el culto, la observancia, la práctica y la enseñanza. 2. Nadie será objeto de coacción que pueda menoscabar su libertad de tener una religión o convicciones de su elección. 3. La libertad de manifestar la propia religión o las propias convicciones estará sujeta únicamente a las limitaciones que prescriba la ley y que sean necesarias para proteger la seguridad, el orden, la salud o la moral públicos o los derechos y libertades fundamentales de los demás. Artículo 6. De conformidad con el artículo 1 de la presente Declaración y sin perjuicio de lo dispuesto en el párrafo 3 del artículo 1, el derecho a la libertad de pensamiento, de conciencia, de religión o de convicciones comprenderá, en particular, las libertades siguientes: a) la de practicar el culto o de celebrar reuniones en relación con la religión o las convicciones, y de fundar y mantener lugares para esos fines; b) La de fundar y mantener instituciones de beneficencia o humanitarias adecuadas; c) la de confeccionar, adquirir y utilizar en cantidad suficiente los artículos y materiales necesarios para los ritos o costumbres de una religión o convicción; d) La de escribir, publicar y difundir publicaciones pertinentes en esas esferas; e) La de enseñar la religión o las convicciones en lugares aptos para esos fines; f) La de solicitar y recibir contribuciones voluntarias financieras y de otro tipo de particulares e instituciones; g) La de capacitar, nombrar, elegir y designar por sucesión los dirigentes que correspondan según las necesidades y normas de cualquier religión o convicción; h) La de observar días de descanso y de celebrar festividades y ceremonias de conformidad con los preceptos de una religión o convicción; j) La de establecer y mantener comunicaciones con individuos y comunidades acerca de cuestiones de religión o convicciones en el ámbito nacional y en el internacional.

41 Artículo 2: 1. Nadie será objeto de discriminación por motivos de religión o convicciones por parte de ningún Estado, institución, grupo de personas o particulares. 2. A los efectos de la presente Declaración, se entiende por “intolerancia y discriminación basadas en la religión o las convicciones" toda distinción, exclusión, restricción o preferencia fundada en la religión o en las convicciones y cuyo fin o efecto sea la abolición o el menoscabo del reconocimiento, el goce o el ejercicio en pie de igualdad de los derechos humanos y las libertades fundamentales.

42 Artículo 3: La discriminación entre los seres humanos por motivos de religión o convicciones constituye una ofensa a la dignidad humana y una negación de los principios de la Carta de las Naciones Unidas, y debe ser condenada como una violación de los derechos humanos y las libertades fundamentales proclamados en la Declaración Universal de Derechos Humanos y enunciados detalladamente en los Pactos internacionales de derechos humanos, y como un obstáculo para las relaciones amistosas y pacíficas entre las naciones. 


\subsubsection{Carta de los Derechos Fundamentales de la Unión Europea (2000) ${ }^{43}$}

El texto, proclamado por el Parlamento y la Comisión Europea así como por el Consejo de la Unión Europea, contiene disposiciones sobre derechos humanos. Inicialmente, la doctrina $^{44}$ ha subrayado las dudas existentes acerca de su naturaleza jurídica y su valor aceptado que estamos ante actos jurídicos de naturaleza no obligatoria, si bien se interpreta que llegará a ser obligatoria a través de su interpretación por el Tribunal de Justicia de las Comunidades europeas en tanto que síntesis y expresión de los principios generales del Derecho comunitario ${ }^{45}$. En su artículo 10 recoge la libertad de pensamiento, conciencia y religión así como la objeción de conciencia de acuerdo con las leyes nacionales ${ }^{46}$. Gracias a la jurisprudencia del Tribunal de Justicia, que se ha incorporado en los tratados, la tutela de la libertad religiosa se ha producido en la Unión Europea. En opinión de CASTRO JOVER ${ }^{47}$ el Tratado por el que se establece una Constitución para Europa firmado en Roma el 2004 ha constituido un punto de inflexión, ya que ha incorporado la Carta en el texto y al dotar a la Unión de personalidad jurídica ha hecho posible la adhesión al Convenio europeo para la protección de derechos fundamentales. Por otra parte, el Tratado de Lisboa, además de mantener el lugar prevalente de los derechos fundamentales, no ha alterado el valor jurídico de la Carta que se incorpora como declaración en el anexo del Acta final, ni ha modificado el instrumento de desarrollo mediante ley.

\subsection{Carta de los Derechos Fundamentales de la Unión Europea (2000)}

\subsubsection{La Constitución española (1978) $)^{48}$}

Como se sabe, la Constitución española de 1978, se refiere a la libertad religiosa ${ }^{49}$ en

\footnotetext{
${ }^{43}$ Accesible en: http://www.europarl.europa.eu/charter/pdf/text es.pdf. La nueva versión de este texto ha entrado en vigor con el Tratado de Lisboa, cuya ratificación se ha producido por la LO 1/2008, de 30 de julio, en el BOE núm. 184 de 31 de julio, con corrección de errores en el BOE núm. 98 de 22 de abril de 2009. Sobre él véase por ejemplo: RUIZ MIGUEL, C., (Coord.), Estudio sobre la Carta de los Derechos Fundamentales de la Unión Europea, Universidad de S. de Compostela, Santiago de Compostela 2004; AAVV., (Dra., MANGAS MARTÍN, A.), Carta de los Derechos fundamentales de la Unión Europea. Comentario artículo por artículo. Fundación BBVA, Bilbao 2008; PAREJO NAVAJAS, T., "La carta de los derechos fundamentales de la Unión Europea", Derechos y Libertades. Revista del Instituto Bartolomé de las Casas, 22 (2010) 205-239 y sobre todo: AAVV, (Ed. MEYER, J.), Charta der Grundrechte der Europäischen Union, 3. Ed., Nomos, Baden-Baden 2011.

44 CARRILlO SALCEDO, J. A., "Notas sobre el significado político y jurídico de la Carta de Derechos Fundamentales de la Unión Europea", Revista de Derecho Comunitario Europeo, 5, 9 (2001) 7-26.

${ }^{45}$ CARRILlO SALCEDO, Notas cit., 19.

${ }^{46}$ Libertad de pensamiento, de conciencia y de religión. 1. Toda persona tiene derecho a la libertad de pensamiento, de conciencia y de religión. Este derecho implica la libertad de cambiar de religión o de convicciones, así como la libertad de manifestar su religión o sus convicciones individual o colectivamente, en público o en privado, a través del culto, la enseñanza, las prácticas y la observancia de los ritos. 2. Se reconoce el derecho a la objeción de conciencia de acuerdo con las leyes nacionales que regulen su ejercicio. Comentario del artículo en: MARTÍN SÁNCHEZ, I., "La protección de las libertades de conciencia, religiosa y de enseñanza en la Unión Europea", Revista General de Derecho Canónico y Derecho Eclesiástico del Estado, 2 (edición electrónica) en http://www.iustel.com así como MARTÍN Y PÉREZ DE NANCLARES, J., “Artículo 10: Libertad de pensamiento, de conciencia y de religión”, en AAVV, (Dra., MANGAS MARTÍN, A.), Carta cit., 256-269.

${ }^{47}$ CASTRO JOVER, La tutela cit., 96 ss.

${ }^{48}$ BOE, núm. 311, de 29 diciembre. Comentando en general dicho cuerpo jurídico véase, a título de ejemplo: AAVV, (Dres. CASAS BAAMONDE, M. E., et al.), Comentarios a la Constitución española: XXX aniversario. Wolters Kluwer España, Madrid 2009.

${ }^{49}$ Sobre esta cuestión concreta vid. por ejemplo: LLAMAZARES FERNÁNDEZ, D.- SUÁREZ PERTIERRA, G., "El fenómeno religioso en la nueva Constitución española. Bases de su tratamiento jurídico", Revista de la Facultad de Derecho de la Universidad Complutense, 61(1980) 7-34; AAVV, (Ed. MARTÍNEZ-TORRÓN, J.), Estado y religión en la Constitución Española y en la Constitución Europea, Comares, Granada, 2006.
} 
el artículo $16^{50}$ que inicia la sección primera del capítulo dedicado a los derechos fundamentales y libertades públicas ${ }^{51}$, cuando proclama sin vacilación que se garantiza la libertad religiosa y de culto tanto a las personas individuales como a las Comunidades sin más limitaciones que las necesidades del orden público establezcan ${ }^{52}$. Ello se concreta en el máximo respeto tanto a la creencia interna (reconocimiento de un ámbito íntimo de creencias) como a la manifestación externa (que permite a los ciudadanos actuar con arreglo a sus propias convicciones y mantenerlas frente a terceros) así como a la no creencia y su expresión. Además, la relación entre el Estado y las Confesiones religiosas está basada en dos elementos: la separación del Estado de las Confesiones y la neutralidad positiva que implica la intervención de los poderes públicos mediante actividades encaminadas a hacer efectivo el ejercicio de la libertad a todos por igual ${ }^{53}$.

\subsubsection{La Ley Orgánica de libertad religiosa $(1980)^{54}$}

El desarrollo del derecho fundamental recogido en el texto constitucional se produjo con la promulgación de la Ley Orgánica de Libertad Religiosa de 5 de julio de 1980, ley que en su artículo segundo ${ }^{55}$ especifica el contenido de dicha libertad tanto para personas individuales (reconociéndoles un conjunto de facultades como por ejemplo el profesar las creencias que

${ }_{50}^{50.1 . ~ S e ~ g a r a n t i z a ~ l a ~ l i b e r t a d ~ i d e o l o ́ g i c a, ~ r e l i g i o s a ~ y ~ d e ~ c u l t o ~ d e ~ l o s ~ i n d i v i d u o s ~ y ~ l a s ~ c o m u n i d a d e s ~ s i n ~ m a ́ s ~ l i m i t a c i o ́ n, ~}$ en sus manifestaciones, que la necesaria para el mantenimiento del orden público protegido por la Ley. 2. Nadie podrá ser obligado a declarar sobre su ideología, religión o creencias.

${ }^{51}$ Además, el capítulo II de la Carta Magna bajo el rótulo de Derechos y Libertades, inicia su articulado con una referencia indirecta a nuestro tema al impedir la discriminación por razón de religión (Artículo 14. Los españoles son iguales ante la Ley, sin que pueda prevalecer discriminación alguna por razón de nacimiento, raza, sexo, religión, opinión o cualquier otra condición o circunstancia personal o social).

52 Véase por ejemplo el breve comentario en LLAMAZARES, Derecho, Vol. I, cit., 325 ss.

${ }^{53} \mathrm{Al}$ respecto desarrollando el tema con profundidad: CASTRO JOVER, A., "Laicidad y actividad positiva de los poderes públicos", Revista General de Derecho Canónico y Derecho Eclesiástico del Estado 3(2003) accesible en: http://www.iustel.com/v2/revistas/detalle_revista.asp?id=2\&numero=3.

${ }^{54}$ Ley Orgánica 7/1980, de 5 de julio, de Libertad Religiosa, de ocho artículos, dos disposiciones transitorias, una derogatoria y una final. BOE núm. 177 de 24 de Julio. Vid. por ejemplo: AAVV, La nueva realidad religiosa española: 25 años de la Ley Orgánica de Libertad Religiosa, Ministerio de Justicia. Madrid 2006; AAVV, (Coords. CORSINO ÁLVAREZ CORTINA, A.- RODRÍGUEZ BLANCO M.), La libertad religiosa en España. XXV años de vigencia de la LO 7/1980, de 5 de Julio. (Comentarios a su articulado, Editorial Comares. Granada 2006; AAVV, (Coords. NAVARRO-VALLS, R., - MANTECÓN SANCHO, J., y MARTÍNEZ-TORRÓN, J.), La libertad religiosa y su regulación legal. La Ley Orgánica de Libertad Religiosa, Ed. Iustel, Madrid 2009, Revista General de Derecho Canónico y Derecho Eclesiástico del Estado, 19 (2009). Sección monográfica: La ley orgánica de libertad religiosa: contenido y reforma. En homenaje al Profesor Mariano López Alarcón, accesible en: http://www.iustel.com/v2/ revistas/detalle_revista.asp?id=2\&numero=19.

${ }^{55}$ Artículo 2. Uno. La Libertad Religiosa y de culto garantizado por la Constitución comprende, con la consiguiente inmunidad de coacción, el derecho de toda persona a: a.- Profesar las creencias religiosas que libremente elija o no profesar ninguna; cambiar de confesión o abandonar la que tenía; manifestar libremente sus propias creencias religiosas o la ausencia de las mismas, o abstenerse de declarar sobre ellas. b.- Practicar los actos de culto y recibir asistencia religiosa de su propia confesión; conmemorar sus festividades; celebrar sus ritos matrimoniales; recibir sepultura digna, sin discriminación por motivos religiosos, y no ser obligado a practicar actos de culto o a recibir asistencia religiosa contraria a sus convicciones personales. c.- Recibir e impartir enseñanza a información religiosa de toda índole, ya sea oralmente, por escrito o por cualquier otro procedimiento; elegir para sí, y para los menores no emancipados e incapacitados, bajo su dependencia, dentro y fuera del ámbito escolar, la educación religiosa y moral que esté de acuerdo con sus propias convicciones. d.- Reunirse o manifestarse públicamente con fines religiosos y asociarse para desarrollar comunitariamente sus actividades religiosas de conformidad con el Ordenamiento Jurídico General y lo establecido en la presente Ley Orgánica. Dos. Asimismo comprende el derecho de las Iglesias, Confesiones y Comunidades religiosas a establecer lugares de culto o de reunión con fines religiosos, a designar y formar a sus ministros, a divulgar y propagar su propio credo, y a mantener relaciones con sus propias organizaciones o con otras confesiones religiosas, sean en territorio nacional o en el extranjero. Tres. Para la aplicación real y efectiva de estos derechos, los poderes públicos adoptarán las medidas necesarias para facilitar la asistencia religiosa en los establecimientos públicos militares, hospitalarios, asistenciales, penitenciarios y otros bajo su dependencia, así como la formación religiosa en centros docentes públicos. 
elijan, el practicar los actos de culto de la confesión, el recibir enseñanza o información religiosa o el reunirse, asociarse o manifestarse con fines religiosos) como para Iglesias, Comunidades y Confesiones religiosas (a quienes se les reconoce la facultad de, por ejemplo, establecer lugares de culto, formar y nombrar a sus ministros, etc. $)^{56}$. Además, como no podía ser de otra manera tratándose de un derecho fundamental ${ }^{57}$, la libertad religiosa ostenta una protección jurídica especial a la que se hace referencia en el artículo cuarto ${ }^{58}$. Dicha protección se ve reforzada por la tutela recogida en el vigente Código Penal que castiga las coacciones o actos contrarios a su ejercicio en el capítulo IV, encontrándonos en la sección segunda un apartado especial referido a los delitos contra la libertad de conciencia, los sentimientos religiosos y el respeto a los difuntos ${ }^{59}$.

Ahora bien, delimitar su contenido no es sencillo; tal como se había establecido en la propia Constitución ${ }^{60}$, el ejercicio de la libertad religiosa tiene límites a los que la ley orgánica menciona en su artículo tercero ${ }^{61}$ y que vienen fijados por el “orden público". El legislador intenta precisar este tópico concepto y señala sus elementos constitutivos: la protección del derecho de los demás al ejercicio de sus libertades públicas y derechos fundamentales y la salvaguardia de la seguridad, de la salud y de la moralidad pública. Sin embargo, han tenido que ser los tribunales los que se encarguen de precisar su contenido haciendo con ello posible la necesaria convivencia entre diferentes religiones en una sociedad como la española, en la que tradicionalmente el catolicismo ha sido religión única y sigue siendo la religión mayoritaria. La sociedad multicultural actual hace que el acceso o no al Registro de Entidades Religiosas, su financiación, la enseñanza de disciplinas religiosas, la dificultad, en particular de las alumnas de emplear pacíficamente determinados atuendos en centros de enseñanza, la presencia de símbolos religiosos en las aulas, el ejercicio de la libertad de expresión sin incurrir en difamaciones religiosas, el ejercicio de la

${ }^{56}$ Al respecto: SOUTO GALVÁN, B., El reconocimiento estatal de las entidades religiosas, Universidad Complutense, Madrid, 2000; POLO SABAU, J. R., La naturaleza jurídica de las confesiones religiosas en el derecho constitucional español, Serv. Publicaciones Universidad de Málaga, Málaga 2008; PALOMINO, R., "Iglesias, Confesiones y Comunidades Religiosas: el concepto legal de confesión religiosa en la LOLR y la doctrina”, Revista General de Derecho Canónico y Derecho Eclesiástico del Estado, 19 (2009) cit., en: http://www.iustel.com/v2/revistas/detalle_revista.asp? $\mathrm{id}=2 \&$ numero $=19$.

${ }^{57}$ Es preciso recordar que el artículo 53.2 de la Constitución establece que "cualquier ciudadano podrá recabar la tutela de las libertades y derechos reconocidos en el artículo 14 y la sección primera del capítulo segundo ante los Tribunales ordinarios por un procedimiento basado en los principios de preferencia y sumariedad y, en su caso, a través del recurso de amparo ante el Tribunal Constitucional".

${ }^{58}$ Artículo cuarto. Los derechos reconocidos en esta Ley ejercitados dentro de los límites que la misma señala serán tutelados mediante amparo judicial ante los Tribunales Ordinarios y amparo constitucional ante el Tribunal Constitucional en los términos establecidos en su ley Orgánica.

${ }^{59}$ Concretamente los artículos 522-526 que tratan de: a.- el impedir o forzar la práctica de actos religiosos, b.- el impedir o perturbar actos de confesiones religiosas; c.- de los actos de profanación en lugar destinado al culto; d.- el escarnio y e.- la violación de sepulturas y profanación de cadáveres. Sobre aspectos concretos vid: OLMOS ORTEGA, E., "La tutela de las entidades religiosas en el Código Penal de 1995", Cuadernos Constitucionales de la Cátedra Fadrique Furió Ceriol, 2a . época, 17 (1996) 137-146; RAMÍREZ NAVALÓN, R. M., "La protección penal del derecho de libertad religiosa: valoración crítica de su regulación en el vigente Código Penal de 1995”, Estudios Jurídicos en Memoria del Profesor Dr. D. José Ramón Casabó Ruiz, Universidad de Valencia, Valencia 1997, 655-670 y FERREIRA GALGUERA, J., Protección jurídico penal de la religión, Universidade da Coruña, La Coruña 1998.

${ }^{60}$ Véase en la nota 49 reproducido el artículo 16.1 de la Constitución.

${ }^{61}$ Artículo Tercero. Uno. El ejercicio de los derechos dimanantes de la Libertad Religiosa y de Culto tiene como único límite la protección del derecho de los demás al ejercicio de sus libertades públicas y derechos fundamentales, así como la salvaguardia de la seguridad, de la salud y de la moralidad pública, elementos constitutivos del orden público protegido por la Ley en el ámbito de una sociedad democrática. Dos. Quedan fuera del ámbito de protección de la presente Ley las actividades, finalidades y entidades relacionadas con el estudio y experimentación de los fenómenos psíquicos o parapsicológicos o la difusión de valores humanísticos o espirituales u otros fines análogos ajenos a los religiosos. 
libertad religiosa en las fuerzas armadas, etc., ${ }^{62}$ se hayan convertido en cuestiones debatidas sobre las que los tribunales de diversas instancias se han ido pronunciando delimitando el contenido de libertad religiosa y su límite, siendo al final el Tribunal Constitucional ${ }^{63}$, a nivel nacional, y el Tribunal de Derechos Humanos de Estrasburgo ${ }^{64}$, a nivel europeo, los que, al determinar en cada caso qué ha de entenderse por orden público ${ }^{65}$, vienen fijando el contenido de la libertad religiosa.

\section{El Mañana}

\subsection{Perspectivas de reforma}

La tutela de la libertad religiosa es incuestionable en nuestro ordenamiento jurídico; sin embargo, hay voces críticas respecto de algunos aspectos de su regulación ${ }^{66}$. Así, tras los acuerdos firmados con las Confesiones Religiosas se alude a la existencia de un régimen jurídico plural. Por un lado, el surgido de los Tratados Internacionales entre el Estado Español y la Santa Sede $^{67}$ y por otro, el nacido de los acuerdos ${ }^{68}$ entre el Estado con la Federación de Entidades Religiosas Evangélicas ${ }^{69}$, con las Comunidades israelitas ${ }^{70} \mathrm{y}$ con la Comisión Islámica ${ }^{71}$. Además, está el régimen aplicable a las Confesiones simplemente inscritas que no han firmado acuerdo

62 Una extensa exposición de, entre otras, la regulación de estas cuestiones en: LLAMAZARES FERNÁNDEZ, D., - LlamaZARES CAlZADILlA, M. C., Derecho de la Libertad de Conciencia. Vol. II, Conciencia, identidad personal y solidaridad, 4. Ed., Civitas, Cizur Menor 2011.

${ }^{63}$ Un resumen de su interpretación sobre todo en: LLAMAZARES, Derecho, Vol. I, cit., 312 ss.; LIBERTAD. La libertad religiosa en España a los veinte años de su Ley orgánica /España. Ministerio de Justicia, Ministerio de Justicia, Madrid 1999; ROSSELL, J., "El concepto y contenido del derecho de libertad religiosa en la doctrina científica española y su incidencia en la jurisprudencia del Tribunal Constitucional", Anuario de Derecho Eclesiástico del Estado, 15 (1999) 87-128; LÓPEZ CASTILLO, A., La libertad religiosa en la jurisprudencia constitucional, Aranzadi, Cizur Menor 2002; La libertad religiosa en el Tribunal Constitucional y en el Tribunal Supremo (1979-2004). Ministerio de Justicia. Madrid 2005.

${ }^{64}$ La obra de TAYLOR, Freedom cit., recoge y comenta múltiples sentencias de este tribunal. Comenta también este punto: CASTRO JOVER, La tutela cit., $114 \mathrm{ss.}$

65 Sobre el mismo véase a título de ejemplo: CALVO-ÁLVAREZ, J., Orden público y factor religioso en la Constitución española. Universidad de Navarra, Pamplona 1983; MARTÍN-RETORTILLO BAQUER, L., "El orden público como límite al derecho de libertad religiosa", AAVV, (Coord. RAMÍREZ JIMENEZ, M.), El desarrollo de la Constitución española de 1978. Libros Pórtico, Zaragoza 1982, 111-143; CARRETERO SÁNCHEZ, S., "Orden público y Poder político ante el fenómeno intercultural religioso: la dificultosa neutralidad del Estado", Actualidad administrativa, 5 (2011) 575ss.

${ }^{66}$ LLAMAZARES, Derecho, Vol. I, cit., 394 ss. habla de problemas del Derecho Eclesiástico español.

67 Son varios: 1.- Acuerdo de 28 de Julio de 1976 (BOE núm. 230 de 24 de septiembre) sobre nombramientos de arzobispos, obispos y vicario general castrense y relaciones con autoridades civiles. Instrumento de ratificación 19 Agosto 1976; 2.-Acuerdo de 3 de enero de 1979 sobre asuntos jurídicos; 3.-Acuerdo de 3 de enero de 1979 sobre asuntos económicos; 4.- Acuerdo de 3 de enero de 1979 sobre enseñanza y asuntos culturales; 5.-Acuerdo de 3 de enero de 1979 sobre asistencia religiosa a las fuerzas armadas y servicio militar de clérigos y religiosos. Todos ellos en el BOE núm. 300 de 15 de diciembre; Instrumento de ratificación 4 diciembre 1979.

68 Véase al respecto por ejemplo: CASTRO JOVER, A., «El desarrollo de la libertad religiosa a partir de la Constitución de 1978: breves consideraciones acerca de la firma de los acuerdos con las minorías religiosas», AAVV, (Coords. REINA, V. - FÉLIX BALlESTA, M. A.), Congreso Internacional de Derecho Eclesiástico del Estado $\left(7^{\circ}\right.$. 1994. Barcelona). Acuerdos del Estado español con las confesiones religiosas minoritarias: actas del VII congreso internacional de Derecho Eclesiástico del Estado, Barcelona 1994, Marcial Pons, Madrid 1996, 523-536.

${ }^{69}$ Ley 24/1992, de 10 de noviembre (BOE núm. 272, de 12 de noviembre), acuerdo de cooperación del Estado con la Federación de entidades religiosas evangélicas de España.

${ }^{70}$ Ley 25/1992, de 10 de noviembre (BOE núm. 272, de 12 de noviembre), acuerdo de cooperación del Estado con la Federación de Comunidades Judías de España.

${ }^{71}$ Ley 26/1992, de 10 de noviembre (BOE núm. 272, de 12 de noviembre), acuerdo de cooperación del Estado con la Comisión Islámica de España. 
alguno. Esta pluralidad normativa, en la práctica, da lugar a un régimen dispar. Así por ejemplo, el Estado español ha financiado la actividad de la Iglesia Católica a través del sistema de asignación tributaria y, en consecuencia, de manera diversa a la del resto de las Confesiones. Igualmente han surgido problemas con los profesores de religión católica en los centros educativos. Sirvan estos ejemplos para reivindicar la necesidad de una nueva regulación que no produzca trato discriminatorio ni entre las personas por su creencia religiosa, ni entre las Confesiones como tal ${ }^{72}$.

\section{ARTIGO 18: O DIREITO À LIBERDADE RELIGIOSA}

Resumo: O presente artigo, embasado no art. 18 da Declaração Universal dos Direitos Humanos, examina os principais textos jurídicos afins, em ordem cronológica, sobre direito à liberdade religiosa, promulgados em níveis internacional, europeu e doméstico.

Palavras-chave: Religião. Liberdade religiosa. Direitos Humanos.

Data de recebimento: mar/2013 - Data de aprovação: mar/2013

\footnotetext{
72 Se pronuncian al respecto: CAÑAMARES ARRIBAS, S., "La Ley Orgánica de Libertad Religiosa: oportunidad y fundamento de una reforma", Ius Canonicum, 50, Num. Extra 100 (2010) 477-515 y MESEGUER VELASCO, S., "Claves para una discutida reforma de la Ley Orgánica de Libertad religiosa", Anuario Jurídico Villanueva, 4 (2010) 211-224.
} 